\title{
Serum lactate as predictor and diagnostic biomarker of plasma leakage in adult dengue patients
}

\author{
Rika Bur*, Suhendro Suwarto**, Widayat Djoko Santoso**, \\ and Kuntjoro Harimurti*****
}

\section{ABSTRACT}

\section{BACKGROUND}

Dengue fever (DF) and dengue hemorrhagic fever (DHF) are differentiated by the occurrence in DHF of plasma leakage into the interstitial space as shown by pleural and peritoneal effusion, hemoconcentration, and intravascular hypovolemia. Perfusion dysfunction causes anaerobic metabolism, which leads to increased serum lactate. This study was to determine serum lactate as prognostic predictor and diagnostic biomarker of plasma leakage in adult dengue patients.

\section{METHODS}

A cross-sectional retrospective cohort study was conducted on 57 adult dengue patients hospitalized in the internal medicine ward of Cipto Mangunkusumo Hospital and Persahabatan Hospital in Jakarta. Serum lactate was examined to determine its mean difference between DF and DHF. The data was analyzed by independent t-test and the cut-off points were identified for presence as well as absence of plasma leakage, then the receiver operating characteristics (ROC) curve was used to determine sensitivity and specificity.

\section{RESULTS}

Mean serum lactate was significantly higher in DHF than in DF. From the ROC curve, the cut-off point for serum lactate as prognostic predictor on day 3 of fever was $\geq 2.65 \mathrm{mmol} / \mathrm{L}$ with AUC of 0.626 (95\% CI 0.480 $0.772 ; \mathrm{p}=0.108)$. The cut-off point for diagnostic biomarker of plasma leakage on day 5 of fever was $\geq 2.55 \mathrm{mmol} / \mathrm{L}$ with sensitivity $66.6 \%$, specificity 54.2\%, and AUC 0.668 (95\% CI 0.550-0.826; p=0.016).

\section{CONCLUSION}

There was a significant difference in serum lactate between DF and DHF. In the critical phase, serum lactate of $\geq 2.55 \mathrm{mmol} / \mathrm{L}$ could be used as plasma leakage diagnostic marker of low accuracy.

Keywords: Dengue virus infection, plasma leakage, serum lactate, adult
*Department of Internal Medicine, Faculty of Medicine, University of Indonesia-RSUPN Cipto Mangunkusumo,

Jakarta Indonesia

**Division of Tropical and Infectious Disease,

Department of Internal Medicine, Faculty of Medicine, University of IndonesiaRSUPN Cipto Mangunkusumo, Jakarta, Indonesia *** Clinical Epidemiology and Evidence-based Medicine (CEEBM) Unit, Faculty of Medicine, University of IndonesiaRSUPN Cipto Mangunkusumo, Jakarta, Indonesia

\section{Correspondence:}

dr. Rika Bur, Sp.PD-KPTI

Department of Internal Medicine, Faculty of Medicine, University of IndonesiaRSUPN Cipto Mangunkusumo, Jakarta, Indonesia J1. Salemba Raya no.6, Jakarta Phone: +628129927 394 Email: krekot09@gmail.com 


\section{INTRODUCTION}

Dengue infection remains a global health problem. Over half of the world population is thought to live in areas at risk of transmission, and recent estimates suggest that around 400 million infections occur annually, of which 100 million are clinically apparent. ${ }^{(1)}$ In 2010 , the Indonesian Ministry of Health reported 150,000 cases of dengue hemorrhagic fever (DHF) with mortality of 1317 cases. $^{(2)}$ In 2013, more than 110,000 DHF cases with mortality of 871 cases were reported. ${ }^{(3)}$

Plasma leakage is the main process in DHF of which clinicians should be aware. ${ }^{(4)}$ Plasma leakage usually occurs when fever is decreased in the critical phase and reaches its peak on the fifth day after the onset of fever. ${ }^{(5-7)}$ In the critical phase, plasma leakage can lead to worse conditions that can cause shock and death. Since plasma leakage is the main characteristic of DHF or dengue shock syndrome (DSS), it will be a great indicator for determining DHF severity. ${ }^{(8)}$ According to the WHO a case of DHF is defined if there is plasma leakage which can be detected by hematocrit elevation of $>20 \%$ from baseline and or hematocrit reduction from baseline of at least $20 \%$ after fluid resuscitation, accompanied by signs of fluid accumulation in the interstitial space, such as pleural effusion and ascites. ${ }^{(9)}$ The latter can be detected through chest radiography and abdominal USG, which however requires expertise and is expensive. Alternatively, plasma leakage can also be seen from laboratory tests for hypoalbuminemia. ${ }^{(10)}$ Regrettably, in daily practice hematocrit baseline values are not readily available and calculation of the degree hematocrit elevation is difficult. Furthermore, baseline hematocrit level may also be affected by conditions such as anemia, which can lead to a misleading diagnosis and inadequate therapy. ${ }^{(11,12)}$

Serum lactate may reportedly be used as a marker of tissue hypoxia caused by systemic hypoperfusion. ${ }^{(13)}$ Serial serum lactate measurement can predict shock and multi-organ failure (MOF), and high lactate levels can be used as predictors of survival or mortality in patients with trauma or sepsis. ${ }^{(14)}$ However, studies regarding the use of serum lactate level as dengue severity predictor and diagnostic biomarker of plasma leakage are still scarce especially in adult patients, therefore further studies are needed. Studies about the role of serum lactate in diagnosing dengue fever (DF) and predicting plasma leakage have been conducted in children. ${ }^{(15,16)}$ Incidence rates of dengue shock syndrome (DSS) are higher in children than in adults. The key factor that distinguishes this condition is associated with vascular fragility. ${ }^{(17)}$

The role of serum lactate as diagnostic biomarker in adult dengue patients was reported previously by Thanachartwet et al. ${ }^{(18)}$, who found that a cut-off value at plasma venous lactate levels of $\geq 2.5 \mathrm{mmol} / \mathrm{L}$, with sensitivity and specificity of $65.0 \%$ and $96.2 \%$, respectively, could identify severe dengue in adult patients. As prognostic factor, they suggested the combination of procalcitonin level $\geq 0.7 \mathrm{ng} / \mathrm{ml}$ and serum lactate $\geq 2.5 \mathrm{mmol} / \mathrm{L}$ for predicting DSS. ${ }^{(19)}$ The present study was intended to re-evaluate the role of serum lactate as predictor of dengue severity and diagnostic biomarker of plasma leakage in adult Indonesian dengue patients.

\section{METHODS}

\section{Research design}

This retrospective cohort study used secondary data (medical records) of adult dengue patients who were enrolled in ongoing research related to dengue fever in Cipto Mangunkusumo Hospital and Persahabatan Hospital in Jakarta. The study was conducted between April 2015 and March 2016.

\section{Study subjects}

Data collection was performed by consecutive non-random sampling. The inclusion criteria were patients with a diagnosis of dengue virus infection through positive NS1 antigen (a non structural protein of the dengue virus) tests on the first and second day of fever, above 14 
years of age, and hospitalized in the Internal Medicine Ward of Cipto Mangunkusumo Hospital and Persahabatan Hospital between 2014 and 2015. The exclusion criteria were pregnant patients and those with incomplete medical records. Dengue hemorrhagic fever patients were defined by hematocrit elevation of $>20 \%$ on the fifth day as compared to baseline and or the presence of pleural effusion or ascites by abdominal USG.

We used the sample size calculation method for the comparison of two independent means and the diagnostic test formula. ${ }^{(20,21)}$ For sample size calculation by the two independent means formula, we used the study by Santosa et al., ${ }^{(8)}$ who reported a mean and standard deviation of $2.81 \pm 0.62$ in the plasma leakage group $(\mathrm{n}=19)$ and of $2.36 \pm$ 0.46 in the non-plasma leakage group $(n=30)$. In our study, the calculated sample size per group was 17 , which was estimated to be adequate to detect a difference in means of 0.44 between the two groups using a two-tailed test, an alpha of 0.05 and power of $90 \%$. Therefore the total minimum sample was 35 patients. Using the formula for diagnostic test, ${ }^{(21)}$ we found that the total minimum sample size was 57 patients, which was estimated to be adequate for a sensitivity of $90 \%$, precision of $10 \%$ and dengue prevalence of $0.61{ }^{(22)}$ From the results of the two formulas, we used the largest calculated minimum sample size, which was 57 patients.

\section{Measurements}

Data taken at the time of admission were the patients' identity such as name, age, gender, date of birth and address. From the patients' history we retrieved data about onset of fever and other clinical symptoms such as nausea, vomiting, heartburn, headache and myalgia. Vital signs such as blood pressure, heart rate, respiratory rate, and temperature were obtained through physical examination.

Data taken during hospitalization were bleeding manifestations, such as positive tourniquet tests, petechiae, gingival bleeding, epistaxis, menometrorrhgia, hematemesis, and melena. From the physical examination we obtained the presence or absence of hepatomegaly. The presence or absence of as cites and pleural effusion was determined by USG.

\section{Laboratory analysis}

This study measured serial complete blood counts and serum lactate, aspartate transaminase (AST) and alanine transaminase (ALT) on the third and fifth days after the onset of fever.

\section{Statistical analysis}

All data was inserted into the patient forms and processed according to the aim of this study. Subject characteristics were descriptively displayed in table form with SPSS (Statistical Package for the Social Sciences) version 20.0. Independent t-test was used to analyze the differences in mean serum lactate on the third and fifth days and in mean basic laboratory test results between DF and DHF patients. An analysis to determine the diagnostic and prognostic role of serum lactate was done by using the receiver operating characteristics (ROC) curve and calculating the area under the ROC (AUC) with 95\% confidence interval. The serum lactate cutoff points for diagnosis and prognosis of plasma leakage were obtained by determining the highest sensitivity and specificity values from the ROC. To determine the accuracy of the diagnostic test, we also calculated the sensitivity, specificity, positive and negative predictive value (PPV and NPV), as well likelihood ratios. Prognostic ability was calculated by absolute risk (AR) and relative risk (RR) at $95 \% \mathrm{CI}$ for plasma leakage in dengue patients with serum lactate above the cut-off point.

\section{Ethical clearance}

This study used secondary data from medical records therefore informed consent was not necessary. This study has been approved by the Health Research Ethics Committee, Faculty of Medicine, University of Indonesia, and the Cipto Mangunkusumo National Central General Hospital (RSUPN Cipto Mangunkusumo) under no. 412/UN2.F1/ETIK/2015. All data were kept confidential by the researchers. 
Table 1. Distribution of characteristics and clinical features of subjects $(n=57)$

\begin{tabular}{lc}
\hline \multicolumn{1}{c}{ C haracteristic } & n (\%) \\
\hline Age (years), median (IQR) & $23(11)$ \\
Male & $35(61.4)$ \\
Dur ation of fever before admission & \\
2 days & $15(26.3)$ \\
3 days & $42(73.7)$ \\
Accompanying sym ptoms & \\
Nausea & $45(78.9)$ \\
Vomiting & $36(63.2)$ \\
Epigastric pain & $25(43.9)$ \\
Headache & $38(66.7)$ \\
Myalgia & $32(56.1)$ \\
Blood pressure mm Hg, median (IQR) & \\
Systolic & $110(10)$ \\
Diastolic & $70(10)$ \\
Bleeding manifestation & \\
Positive toumiquet test & $34(59.7)$ \\
P etechiae & $25(43.8)$ \\
Gingival bleeding & $1(1.8)$ \\
Epistaxis & $2(7.0)$ \\
\hline
\end{tabular}

* Patients may have reported more than one symptom

** IQR : interquartile range

\section{RESULTS}

A total of 57 adult dengue patients were enrolled in the study. The median age of the patients was 23 years (interquartile range [IQR]: $11)$ and 35 (61.4\%) were male. The most common complaint besides fever was nausea (78.9\%), while the most common bleeding manifestation was a positive tourniquet test $(59.7 \%)$. The characteristics of the subjects are summarized in Table 1.

During monitoring, we found that laboratory findings such as hemoglobin, hematocrit, leukocytes, and platelets on days 3 and 5 corresponded to the course of dengue. However, we found no significant differences in basic laboratory workup results between DF and DHF patients, except the leukocyte count on day 5 and AST level on day 3 (Table 2). On day 3, we found that mean serum lactate level was statistically higher in DHF patients than in DF patients (2.88

Table 2. Distribution of mean of laboratory blood parameters between dengue fever and dengue hemorrhagic fever

\begin{tabular}{|c|c|c|c|}
\hline \multirow[b]{2}{*}{ Variable $^{3}$} & \multicolumn{2}{|r|}{ Group } & \multirow[b]{2}{*}{$\mathbf{p}$} \\
\hline & $\begin{array}{c}\text { Dengue Fever } \\
(n=22)\end{array}$ & $\begin{array}{c}\text { Dengue He morrhagic Fever } \\
\text { (IF 35) }\end{array}$ & \\
\hline \multicolumn{4}{|l|}{ Hemoglobin (g/dl) } \\
\hline Day 3 & $13.65 \pm 1.69$ & $14.37 \pm 1.45$ & 0.104 \\
\hline Day 5 & $13.66 \pm 1.91$ & $14.42 \pm 1.90$ & 0.155 \\
\hline \multicolumn{4}{|l|}{ Hematocrit (\%) } \\
\hline Day 3 & $39.63 \pm 4.16$ & $41.69 \pm 4.68$ & 0.107 \\
\hline Day 5 & $40.22 \pm 4.72$ & $42.22 \pm 5.99$ & 0.168 \\
\hline \multicolumn{4}{|c|}{ Leukocyte count $\left(x_{10}^{3} / \mu \mathrm{L}\right)$} \\
\hline Day 3 & $3.36 \pm 1.31$ & $3.15 \pm 1.38$ & 0.656 \\
\hline Day 5 & $2.20 \pm 1.15$ & $3.82 \pm 1.87$ & 0.033 \\
\hline \multicolumn{4}{|c|}{ P1atel et count $\left(x_{10}^{3} / \mu \mathrm{L}\right)$} \\
\hline Day 3 & $115.09 \pm 32.55$ & $109.36 \pm 40.69$ & 0.595 \\
\hline Day 5 & $70.00 \pm 38.43$ & $56.72 \pm 3435$ & 0.168 \\
\hline \multicolumn{4}{|l|}{ AST (U/L) } \\
\hline Day 3 & $36.91 \pm 14.65$ & $84.18 \pm 40.01$ & 0.003 \\
\hline Day 5 & $73.35 \pm 58.78$ & $140.87 \pm 44.66$ & 0.101 \\
\hline \multicolumn{4}{|l|}{$\mathrm{ALT}(\mathrm{U} / \mathrm{L})$} \\
\hline Day 3 & $32.64 \pm 25.55$ & $45.20 \pm 26.11$ & 0.279 \\
\hline Day 5 & $58.21 \pm 13.95$ & $75.50 \pm 2325$ & 0.504 \\
\hline \multicolumn{4}{|c|}{ Lactate level $(\mathrm{mm}$ ol/L $/ \mathrm{A}$} \\
\hline Day 3 & $2.55 \pm 0.43$ & $2.88 \pm 0.59$ & $0.028 *$ \\
\hline Day 5 & $2.40 \pm 0.55$ & $2.84 \pm 0.55$ & $0.005 *$ \\
\hline
\end{tabular}

${ }^{\mathrm{a}}$ Data presented as mean \pm standard deviation 
Table 3. Diagnostic value of serum lactate levels for dengue severity

\begin{tabular}{|c|c|c|c|c|c|c|c|c|}
\hline & \multicolumn{2}{|c|}{$\begin{array}{l}\text { Dengue } \\
\text { Severity }\end{array}$} & \multirow{2}{*}{$\begin{array}{l}\text { Sensinitity } \\
\text { (55\% CI) }\end{array}$} & \multirow{2}{*}{$\begin{array}{l}\text { Specificity } \\
\text { (95\% CI) }\end{array}$} & \multirow{2}{*}{$\begin{array}{c}\text { PPV } \\
(95 \% \text { CI })\end{array}$} & \multirow{2}{*}{$\begin{array}{c}\text { NPV } \\
05 \% \mathrm{CI})\end{array}$} & \multirow{2}{*}{$\begin{array}{c}\operatorname{LR}(+) \\
(95 \% \mathrm{CT})\end{array}$} & \multirow{2}{*}{$\begin{array}{c}\text { LR }(-) \\
(95 \% \mathrm{CI})\end{array}$} \\
\hline & $\overline{D F}$ & DHF & & & & & & \\
\hline $\begin{array}{l}\text { Lac tate level } \\
\text { Day } 3 \text { cut-off }\end{array}$ & 24 & 33 & $\begin{array}{c}42.5 \% \\
{[0.440 .79]}\end{array}$ & $\begin{array}{c}50.0 \% \\
{[0.29-0.71]}\end{array}$ & $\begin{array}{c}6250 \% \\
{[0.440 .79]}\end{array}$ & $\begin{array}{c}54.2 \% \\
{[0.290 .71]}\end{array}$ & $\begin{array}{c}125 \\
{[0.77-202]}\end{array}$ & $\begin{array}{c}0.75 \\
{[0.41-1.37]}\end{array}$ \\
\hline $\begin{array}{l}\geq 265 \text { mmoliL } \\
\text { Lac tate level } \\
\text { Day } 5 \text { cut-off } \\
\geq 255 \text { mmoll }\end{array}$ & 24 & 33 & $\begin{array}{c}66.6 \% \\
{[0.50-0.80]}\end{array}$ & $\begin{array}{c}54.2 \% \\
{[0.35-0.72]}\end{array}$ & $\begin{array}{c}67 \% \\
{[0.50-0.80]}\end{array}$ & $\begin{array}{c}54 \% \\
{[0.35-0.72]}\end{array}$ & $\begin{array}{c}1.45 \\
{[0.88-239]}\end{array}$ & $\begin{array}{c}0.62 \\
{[0.341 .13]}\end{array}$ \\
\hline
\end{tabular}

$\pm 0.59 \mathrm{mmol} / \mathrm{L}$ vs. $2.55 \pm 0.43 \mathrm{mmol} / \mathrm{L} ; \mathrm{p}=0.028$ ). Serum lactate in DHF patients remained higher than in DF patients on day $5(2.84 \pm 0.55 \mathrm{mmol} /$ L vs. $2.40 \pm 0.55 \mathrm{mmol} / \mathrm{L} ; \mathrm{p}=0.005$ ) (Table 2 ).

We used ROC analysis as a test for the association between serum lactate on the third day and the presence of plasma leakage on the fifth day to determine the role of serum lactate as a predictor of plasma leakage. The results of the analysis showed that serum lactate cannot be used as predictor of plasma leakage (AUC $0.626 ; 95 \%$ CI $0.480-0.772 ; \mathrm{p}=0.108$ ) (Figure 1). The cutoff point of serum lactate on the third day of $\geq 2.65$ $\mathrm{mmol} / \mathrm{L}$ had sensitivity of $42.5 \%$, specificity $50.0 \%$, PPV $62.5 \%$, NPV $54.2 \%$, which was also associated with a 1.20 -fold increased risk $(95 \%$ CI 0.76-1.91) to develop plasma leakage in the critical phase, but this finding was not statistically significant (Table 3 ).

However, the ROC on serum lactate and the presence of plasma leakage on the fifth day showed that serum lactate on the fifth day can be used as diagnostic tool for plasma leakage in DHF patients (AUC 0.688; 95\% CI 0.550$0.826 ; \mathrm{p}=0.016$ ) (Figure 2). The cut-off point of serum lactate on the fifth day of $\geq 2.55 \mathrm{mmol} /$ L had the highest sensitivity $(66.6 \%$; $95 \% \mathrm{CI}$ $0.50-0.80)$ and specificity $(54.2 \%$; $95 \%$ CI $0.35-$ $0.72)$. This cut-off value had PPV $67 \%(95 \%$ CI $0.50-0.80$ ), NPV 54\% (95\% CI 0.35-0.72), positive likelihood ratio LR (+) 1.45 and negative likelihood ratio LR (-) 0.62 (Table 3). Therefore it can be concluded that serum lactate had a low diagnostic accuracy.

ROC Curve

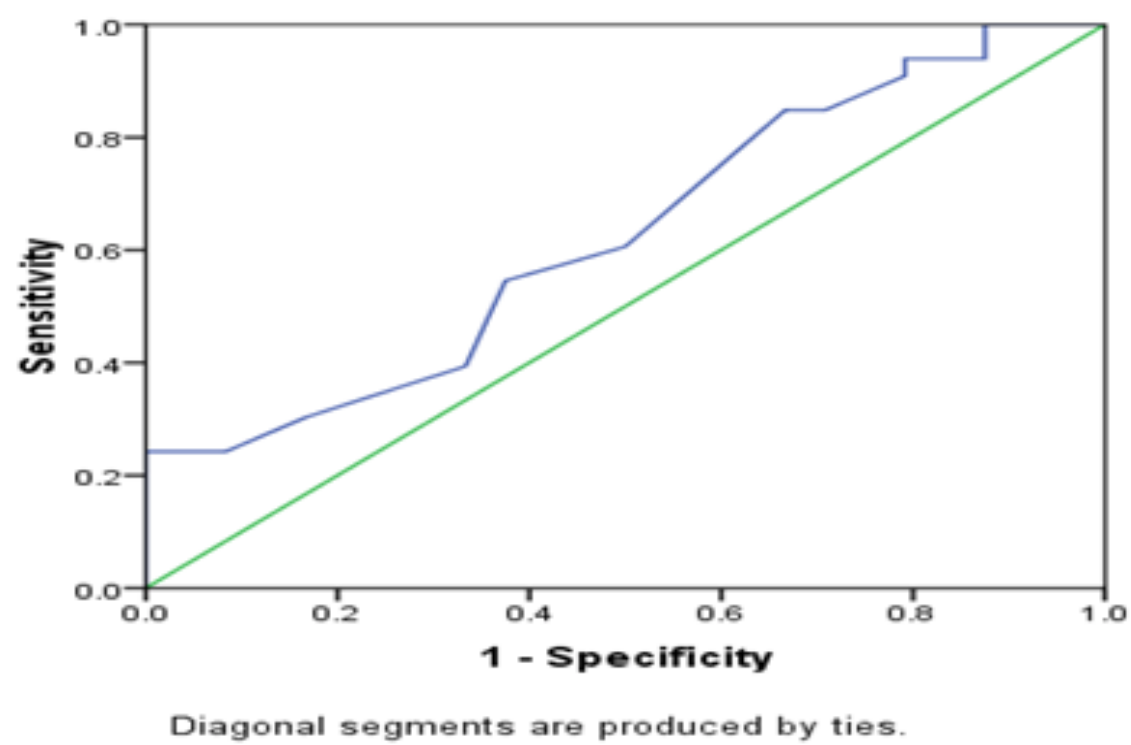

Figure 1. Area under the receiver operating characteristic curve (AUC) for serum lactate level $\geq 2.65 \mathrm{mmol} / \mathrm{L}$ on day 3 as predictor of plasma leakage was 0.626 (95\% CI: $0.480-0.772 ; p=0.108$ ) 
ROC Curve

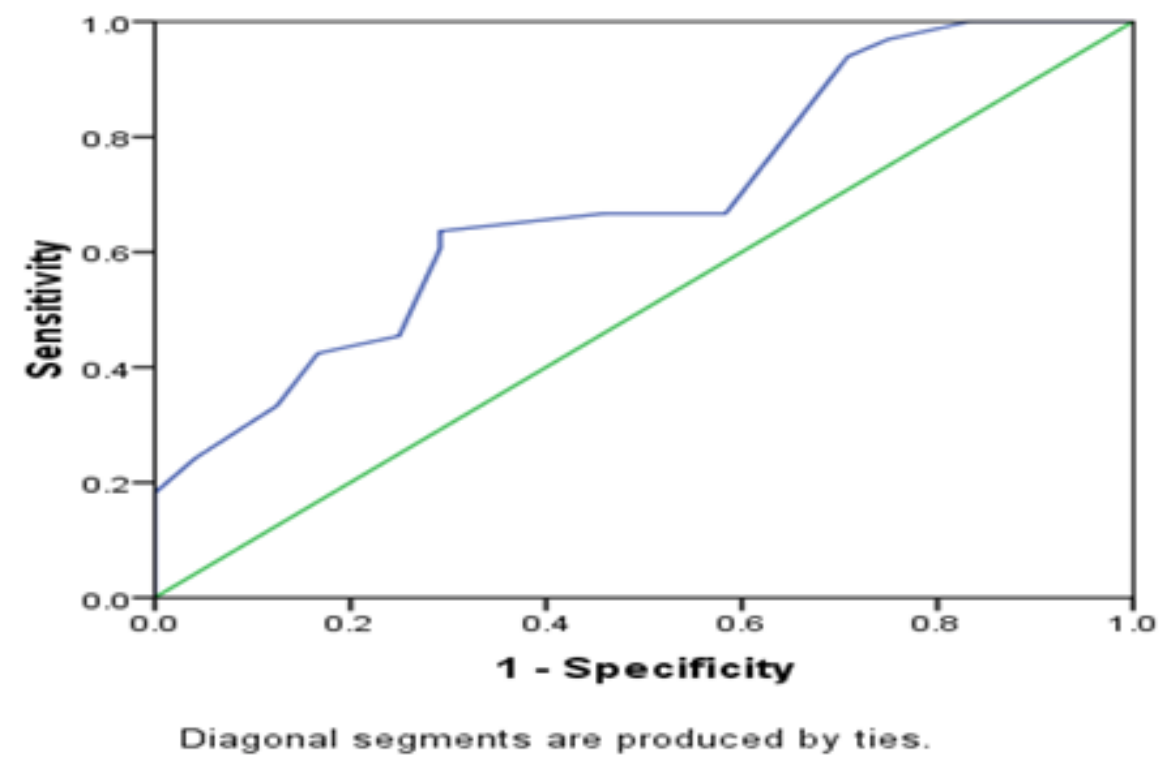

Figure 2. AUC for serum lactate level $\geq 2.55 \mathrm{mmol} / \mathrm{L}$ as diagnostic biomarker of plasma leakage on day 5 was 0.668 [CI 95\% 0.550-0.826; $\mathrm{p}=0.016$ ]

\section{DISCUSSION}

Lactate is a marker for tissue hypoxia that may be the result of anaerobic metabolism mainly due to hypoperfusion. ${ }^{(13)}$ Serum lactate laboratory tests had been incorporated in Surviving Sepsis Campaign (SSC) Guideline 2012 as important workup for all suspected patients with sepsis. ${ }^{(23)}$ The SSC used as cut-off value a serum lactate level of $4 \mathrm{mmol} / \mathrm{L}$ as marker for severe sepsis. Hyperlactatemia is associated with increased mortality in septic patients, therefore it can be used as prognostic factor. Normalization of lactate level also has been suggested as one of the therapeutic goals of sepsis management. ${ }^{(23)}$ While the role of serum lactate in septic patients had been well established, the role of serum lactate as biomarker in dengue patients was understudied, especially in adult patients. In DHF patients the main characteristic finding is plasma leakage from increased vascular permeability, resulting in interstitial edema, pleural effusion, ascites, hemoconcentration, and intravascular hypovolemia. These conditions cause tissue hypoperfusion, which lead to impaired oxygen supply and activation of anaerobic metabolism. ${ }^{(18)}$ Based on dengue pathogenesis, we assessed the role of serum lactate in predicting and diagnosing plasma leakage in adult dengue patients.

In this study, we included 57 adult dengue patients consisting of $22 \mathrm{DF}$ cases and $35 \mathrm{DHF}$ cases. Most of our patients were young male adults, who reported nausea as the most common chief complaint and positive tourniquet test as the most common bleeding manifestation. There are many studies assessing the factors associated with severe dengue or DSS. ${ }^{(24,25)}$ The WHO proposed a list of warning signs, such as abdominal pain, persistent vomiting, mucosal bleed, and lethargy, for predicting severe dengue and the need for strict observation. However, a study by Thanachartwet et al found that the sensitivity and specificity of the 2009 WHO warning signs (except the presence of clinical fluid accumulation) were too low for identifying severe dengue at admission. ${ }^{(18)}$ In our study, among the laboratory parameters we found no significant differences between DF and DHF patients, except leukocyte count on day 5 and AST level on day 3. This finding may have been caused by the adequate fluid resuscitation received by the patients.

Serum lactate values on day 3 and day 5 were found to be significantly higher in DHF patients than in DF patients. A higher lactate level 
may reflect the degree of severity of plasma leakage in DHF patients compared to DF. Sirikutt et al. ${ }^{(16)}$ also reported that serum lactate was found to be elevated in children with DHF and/or DSS. Hyperlactatemia, in addition to being caused by anaerobic metabolism due to hypoperfusion from plasma leakage, may also be caused by impaired lactate clearance from hepatic impairment. ${ }^{(16,26)}$ Therefore, serum lactate may be considered as a marker for the severity of adult dengue patients.

We analyzed the sensitivity and specificity of various cut-off values using ROC to determine the best cut-off point for serum lactate on the third day as a plasma leakage predictor. Serum lactate on the third day of $\geq 2.65 \mathrm{mmol} / \mathrm{L}$ was shown to be nonsignificant in predicting plasma leakage on the fifth day, having a sensitivity of $42.5 \%$, specificity $50.0 \%$, PPV $62.5 \%$, and NPV $54.2 \%$. It can be concluded that serum lactate is nonsignificant as a predictor of plasma leakage in the critical phase. A prospective observational study from Thailand found that the combination of procalcitonin level of $\geq 0.7 \mathrm{ng} / \mathrm{ml}$ and serum lactate level of $\geq 2.5 \mathrm{mmol} / \mathrm{L}$ resulted in a sensitivity of $81.2 \%$, specificity of $84.4 \%$, PPV $56.5 \%$, NPV $94.7 \%$ to predict DSS and/or organ failure. ${ }^{(19)}$ The diagnostic accuracy can be improved if combined with the finding of clinical fluid accumulation, resulting in a sensitivity of $90 \%$ and specificity of $87.6 \%$. These differing findings were presumably the result of differences in the degree of plasma leakage caused by differences in the timing of blood sample collection for serum lactate measurement. The abovementioned study in Thailand used the lactate level at admission for diagnostic accuracy assessment, ${ }^{(19)}$ but we uniformly take blood samples on day 3 which is generally thought as the beginning of plasma leakage. This is presumably done because the degree of plasma leakage is still minimal on day 3 , since plasma leakage in the form of third space fluid accumulation on ultrasound is mostly detected on the fourth and fifth days. ${ }^{(27)}$ Another possible explanation is that because our study was of retrospective design, the patients may have received fluid therapy so that the intravascular volume had been replaced and met the needs for microcirculation. When perfusion is maintained the lactate level may decrease. ${ }^{(28)}$

According to the 1997 WHO guideline, plasma leakage is determined by the presence of hemoconcentration as reflected by increased hematocrit level of $\geq 20 \%$ and/or thrombocytopenia of $<100,000 / \mathrm{mm}^{3}$. A limitation to these criteria is that baseline hematocrit values are commonly not available, and may be misleading in the presence of anemia or hemorrhage and during the early phase of resuscitation. ${ }^{(11,12)}$ Based on ROC, the cut-off point of serum lactate $\geq 2.55 \mathrm{mmol} / \mathrm{L}$ was determined as plasma leakage diagnostic, with sensitivity of $66.6 \%$, specificity $54.2 \%$, PPV $67 \%$ and NPV 54\%. Our cut-off value was slightly different from that reported in the prospective observational study in Thailand which found that the cut-off value of serum lactate level of $\geq 2.5$ $\mathrm{mmol} / \mathrm{L}$ was optimal to identify severe dengue, having a sensitivity of $65 \%$, specificity of $96.2 \%$, PPV of $76.5 \%$, and NPV of $93.5 \% .^{(18)}$ The difference in cut-off values can be explained by the different timing of serum lactate sampling, since we used the serum lactate value on day 3 while the study from Thailand used the lactate value on day 5 .

One limitation of our study was its retrospective cohort design which may be associated with a risk of bias and confounding factors. We suggest that a prospective study be conducted, with blinding of the treating physicians and investigators to the results, to minimize the risk of missing data and bias. For further research, we recommend serial daily serum lactate measurement starting before the third day of the onset of fever, and six-hourly serum lactate measurement during the critical phase until the recovery phase. The clinical implication of our study is that according to the supporting evidence, serum lactate level on the fifth day can be used as diagnostic biomarker of plasma leakage, apart from radiological workup. Therefore early identification and treatment of severe dengue can made, thus resulting in decreased mortality rates. 


\section{CONCLUSIONS}

We found that serum lactate level on the third and fifth days of fever was higher in DHF patients compared to DF patients. Serum lactate level on the third day cannot be used for predicting plasma leakage in the critical phase. Serum lactate on the fifth day can be used for diagnosis of plasma leakage in the critical phase with low accuracy.

\section{CONFLICT OF INTEREST}

The authors declare no competing interest.

\section{ACKNOWLEDGEMENT}

The authors thank the director of Cipto Mangunkusomo National Central General Hospital and Persahabatan General Hospital Jakarta for permission to collect patient data in their respective hospitals.

\section{REFERENCES}

1. Bhatt S, Gething PW, Brady OJ, et al. The global distribution and burden of dengue. Nature 2013; 496:504-7.

2. Kementerian Kesehatan Republik Indonesia. Demam berdarah dengue. Jakarta: Pusat Data dan Surveilans Epidemiologi Kementerian Kesehatan Republik Indonesia;2010.

3. Kementerian Kesehatan Republik Indonesia. Profil kesehatan indonesia 2013. Jakarta: Kementerian Kesehatan Republik Indonesia; 2014.

4. Srikiatkhachorn A. Plasma leakage in dengue haemorrhagic fever. Thromb Haemost 2009; 102: 1042-9.

5. Simmons CP, Farrar JJ, Chau NV, et al. Dengue. N Engl J Med 2012;366:1423-32.

6. Lee YR, Liu MT, Lei HY, et al. MCP-1, a highly expressed chemokine in dengue haemorrhagic fever/dengue shock syndrome patients, may cause permeability change, possibly through reduced tight junctions of vascular endothelium cells. J Gen Virol 2006;87:3623-30.

7. Yacoub S, Mongkolsapaya J, Screaton G. The pathogenesis of dengue. Curr Opin Infect Dis 2013;26:284-9.

8. Santosa D, Alwi EH, Idjradinata PS. Validitas kadar laktat darah dalam mendeteksi kebocoran plasma pada infeksi virus dengue anak. Majalah Kedokteran Indonesia 2011;61:58-62.

9. World Health Organization. Dengue: guidelines for diagnosis, treatment, prevention and control. Geneva: World Health Organization;2009.

10. Villar-Centeno LA, Diaz-Quijano FA, MartinezVega RA. Biochemical alterations as markers of dengue hemorrhagic fever. Am J Trop Med Hyg 2008;78:370-4.

11. Potts JA, Thomas SJ, Srikiatkhachorn A, et al. Classification of dengue illness based on readily available laboratory data. Am J Trop Med Hyg 2010;83:781-8.

12. Kuo MC, Lu PL, Chang JM, et al. Impact of renal failure on the outcome of dengue viral infection. Clin J Am Soc Nephrol 2008;3:13506.

13. Fuller BM, Dellinger RP. Lactate as a hemodynamic marker in the critically ill. Curr Opin Crit Care 2012;18:267-72.

14. Krishna U, Joshi SP, Modh M. An evaluation of serial blood lactate measurement as an early predictor of shock and its outcome in patients of trauma or sepsis. Indian J Crit Care Med 2009; 13:66-73.

15. Puspanjono MT, Latief A, Tumbelaka AR, et al. Comparison of serial blood lactate level between dengue shock syndrome and dengue hemorrhagic fever (evaluation of prognostic value). Paediatrica Indonesiana 2007;47:151.

16. Sirikutt P, Kalayanarooj S. Serum lactate and lactate dehydrogenase as parameters for the prediction of dengue severity. J Med Assoc Thai 2014;97 Suppl 6:S220-31.

17. Halstead SB. The World Health Organization definition of dengue hemorrhagic fever is inadequate for clinical and epidemiological purposes. In: Pascol G, Hoffman SL, editors. Dengue tropical medicine: science and practice. $5^{\text {th }}$ vol. London: Imperial College Press; 2008.p. 427-31.

18. Thanachartwet V, Wattanathum A, Oer-areemitr $\mathrm{N}$, et al. Diagnostic accuracy of peripheral venous lactate and the 2009 WHO warning signs for identifying severe dengue in Thai adults: a prospective observational study. BMC Infect Dis 2016;16:46. doi: 10.1186/s12879-016-1386-5.

19. Thanachartwet V, Desakorn V, Sahassananda D, et al. Serum procalcitonin and peripheral venous lactate for predicting dengue shock and/or organ failure: a prospective observational study. PLoS Negl Trop Dis 2016;10: e0004961. doi:10.1371/ journal.pntd.0004961.

20. Madiyono B, Moeslichan SMZ, Sastroasmoro S, et al. Perkiraan besar sampel. In: Sastroasmoro S, Ismael S, editors. Dasar-dasar metodologi 
penelitian klinis. $5^{\text {th }}$ ed. Jakarta: Sagung Seto; 2014.p.352-87.

21. Hajian-Tilaki K. Sample size estimation in diagnostic test studies of biomedical informatics. J Biomed Informatics 2014;48:193-204.

22. Nainggolan L. Pengembangan sistem skor sebagai prediktor kebocoran plasma pada demam berdarah dengue: peran sTNFR-1, VEGF, sVECADHERIN dalam patofisiologi kebocoran plasma [Disertasi]. Jakarta: Universitas Indonesia;2012.

23. Dellinger RP, Levy MM, Rhodes A, et al. Surviving sepsis campaign: international guidelines for management of severe sepsis and septic shock: 2012. Crit Care Med 2013;41:580637.

24. Huy NT, Van Giang T, Thuy DHD, et al. Factors associated with dengue shock syndrome: a systematic review and meta-analysis. PLoS Negl Trop Dis 2013;7:e2412. doi: 10.1371/journal. pntd.
25. Thanachartwet V, Oer-Areemitr N, Chamnanchanunt $\mathrm{S}$, et al. Identification of clinical factors associated with severe dengue among Thai adults: a prospective study. BMC Infect Dis 2015;15:420.

26. Sterling SA, Puskarich MA, Jones AE. The effect of liver disease on lactate normalization in severe sepsis and septic shock: a cohort study. Clin Exp Emerg Med 2015;2:197-202.

27. Premaratna R, Ragupathy A, Miththinda JK, et al. Timing, predictors, and progress of third space fluid accumulation during preliminary phase fluid resuscitation in adult patients with dengue. Int J Infect Dis 2013;17:e505-9.

28. Bakker J, Nijsten MWN, Jansen TC. Clinical use of lactate monitoring in critically ill patients. Ann Intensive Care 2013;3:12. 